\title{
Vida y Pasión de Santiago el Pajarero*
}

\author{
Por \\ Julio Ramón Ribeyro \\ REPRESENTACION EN SEIS CUADROS
}

La acción se desarrolla en Lima, Ciudad de los Reyes, en la se. Gunda mitad del siglo XVIII, durante el gobierno del Virrey Manuel Amat.

PERSONAJES: (Por orden de aparición)

SANTIAGO, El Pajarero

ROSALUZ, Novia de Santiago

MARIA, Esclava de Rosaluz

BASILIO, El Coplero

BALTAZAR GAVILAN, Escultor

EL DUQUE DE SAN CARLOS, Consejero en Finanzas

ESTEBAN CGONZALVES, BarberOS

EL VIRREY AMAT

cosme- Bueno, Profesor de Matemáticas de la

Universidad de San Marcos

DOS ALGUACILES

UN SECRETARIO

DOS CLIENTES

CUATRO HOMBRES en Ia calle

UN HOMBRE en Ia Galería

VECINO

DIRECTOR del Cuerpo Docente

CATEDRATICOS

PUBLICO.

(Inspirada en una tradición de Don Ricardo Palma)

(*) Esta obra. Premio Nacionat de Teatro 1959, fue estrenada en Lima, el 1a de Oc-
tubre de 1960 , por el grupo "Histrion, Teatro de Arte", bajo la dirección de Hernando Cortég, 


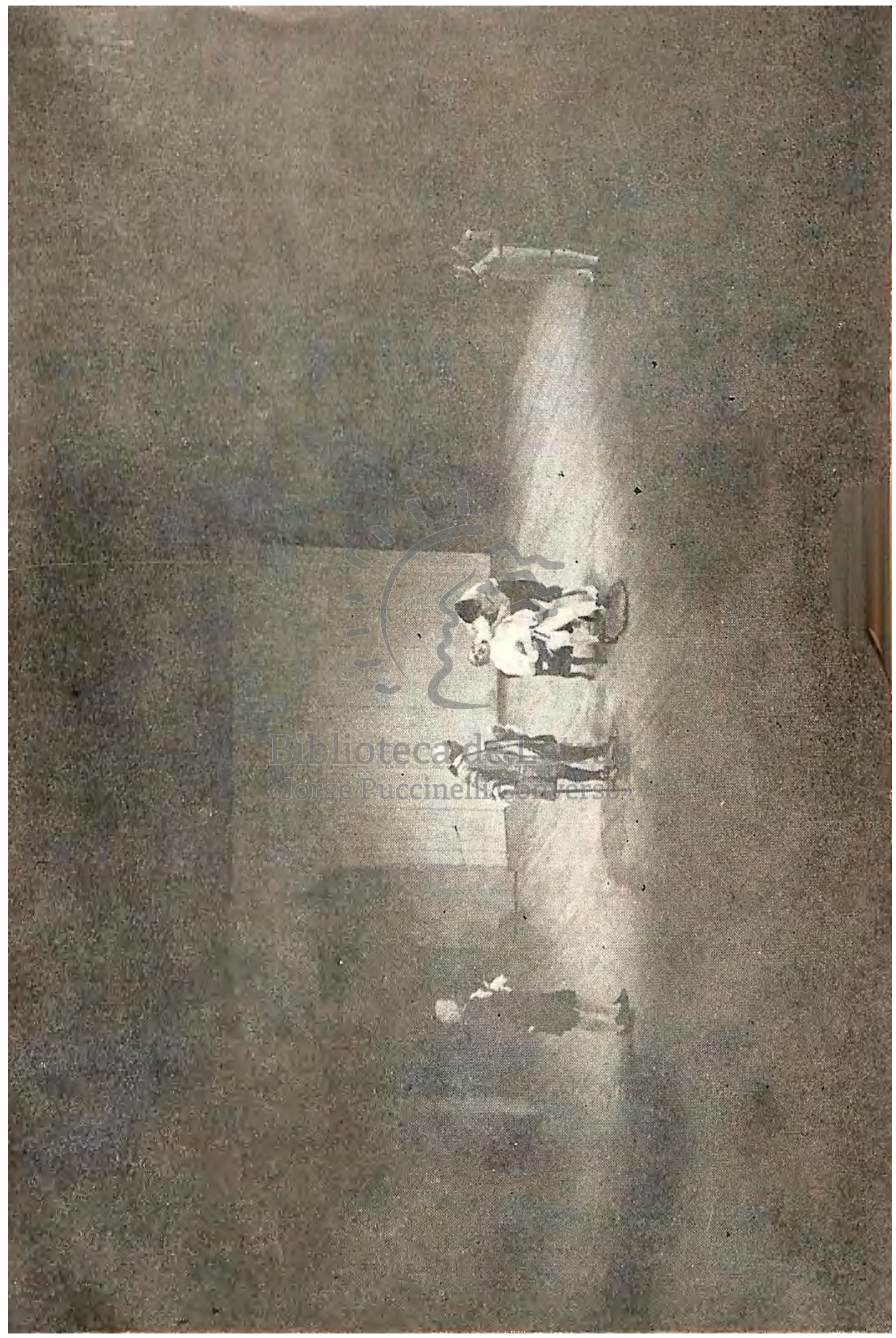




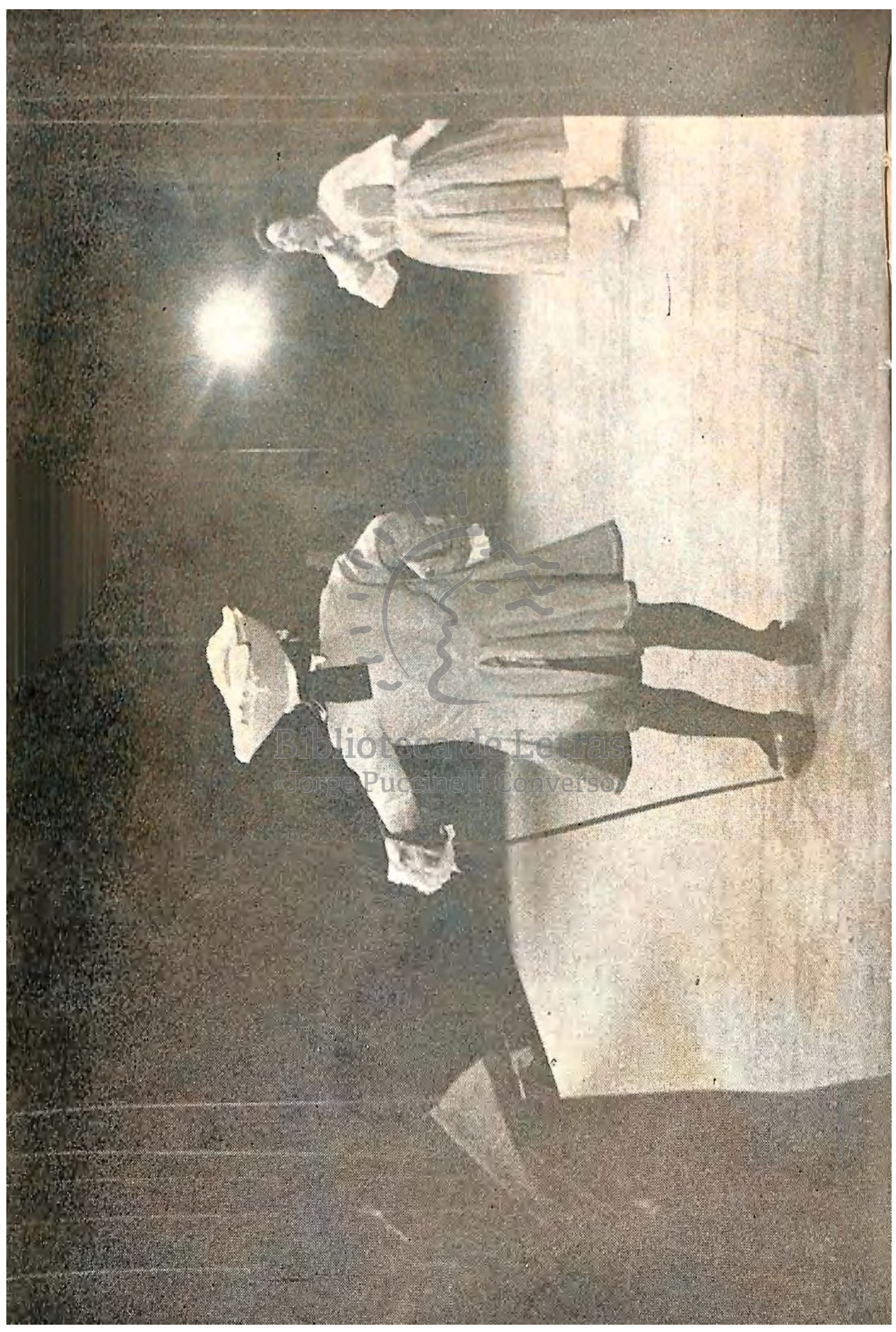




\section{CUADRO PRIMERO}

\section{AL PIE DEL CERRO SAN CRISTOBAL}

Decoración de huerta. Atardecer. Al fondo, perspectiva del San Cristóbal. Santiago, subido en una piedra, mira el follaje de los árboles donde se escuchan los cantos de los pájaros. Rosaluz, con un chal sobre los hombros, da vueltas, impaciente, a su alrededor.

ROSALUZ.-Pero, ¿Qué tanto miras?

SANTIAGO.-iCalla!

ROSALUZ.-¡Bájate de allí y dame el brazo!

SANTIAGO.-iChit!

ROSALUZ.- ¡Para eso me traes aquí, para pasarte la tarde mirando a los pájaros!

SANTIAGO.-No sigas hablando que los vas a espantar.

ROSALUZ.-Soy yo la que me voy a espantar si sigues parado en esas piedras.

(Los cantos cesan, Santiago desciende y da unos pasos, la cabeza en alto, siguiendo el vuelo de los pájaros).

SANTIAGO.- iSe fueron...! La voz humana no los hace muy felices. ¿Me dejas seguirlos un momento? Solamente voy hasta el río. Siéntate aquí y vigila mi jaula.

ROSALUZ.-No puedo demorarme más. Le he dicho a mi mamá que iba a vísperas con María. Las campanas de Los Descalzos ya han tocado.

SANTIAGO,-Solamente unos minutos. Voy hasta el rio y vuelvo.

ROSALUZ.-iNo! Me voy. (Da unos pasos)

SANTIAGO.-( Alcanzándola) Pérdoname, Rosaluz. Soy en verdad poco gentil... Hacerte venir hasta aquí. ¡Pero es que tú no comprendes! ( La ciñe por la cintura) ¿Sabes que cuando era grumete pasé 10 años contemplando los pájaros marinos? En las costas de estas tierras hay millones de pájaros que van de norte a sur y de sur a norte. Durante días enteros siguen a los barcos y forman como un río que palpita en el cielo. Los conozco mejor que a los hombres. Diría que son mis mejores amigos. 
ROSALUZ.-Y por mirar a los pájaros te echaron de la marina.

SANTIAGO.-No fue por eso, Rosaluz. Fue a causa de un naufragio. Pero eso no tiene importancia.

ROSALUZ.- ¿Claro que la tiene! ¿De qué vamos a vivir cuanclo nos casemos? Tu tienda de Botoneros no da ni para regalarme jazmines. Un hombre que cría pájaros, ¿cómo puede fundar una familia? ¡La culpa la tienen tus amigos Basilio y Baltazar! Te juntas con personas sin oficio ni beneficio, con holgazanes que se pasan la vida soñando.

SANTIAGO.-(Herido) Es cierto, no vamos a vivir cle los pájaros. (Misterioso) Pero ellos pueden enseñarnos muchas cosas.

ROSALUZ.-Lo único que pueden enseñarnos es a alimentarnos de mi. gajas. Pero en ese caso prefiero quedarme soltera. En casa de mj madre no me falta nada, gracias a Dios.

SANTIAGO.-(Repite) Pueden enseñarnos muchas cosas los pájaros... ¿Nunca te he dicho en qué ocupo mis noches?

ROSALUZ.-Te irás al "Doblón de Oro", a beber mosto con tus amigos. SANTIAGO.-Te equivocas.

ROSALUZ.- Si, ya sé que me equivoco. o (Mimosa) Me han dicho que velas hasta tarde en tu tienda, ¿verdad?, y que tu luz es la última que se apaga en los portales.

SANTIAGO.-¿Cómo lo sabes?

ROSALUZ.-Me lo dijo el barbero, tu vecino.

SANTIAGO.-(Soñando) A veces velo tanto que veo penetrar el sol por mi ventana.

(Suenan las campanas de Los Descalzos. Rosaluz se santigua)

ROSALUZ.-(Impaciente) iVámonos ya!

SANTIAGO.-Espera.

ROSALUZ.- ¡Haz la" señal de la cruz?

SANTIAGO.-(Se santigua) ¡Soy tan distraído! (Va hasta las piedras y coge su jaula) Mira, ¿sabes lo que es esto?

ROSALUZ.-No sé... Un pájaro como cualquier otro.

SANTIAGO.-Es claro, tú no puedes ver la diferencia.

ROSALUZ.-Lo único que sé es que hace poco volaba libremente y que ahora está prisionero. Eres malo, Santiago, martirizas a las pobres avecillas.

SANTIAGO.-Hacía días que lo acechaba. Este pájaro se llama tijereta. Pero no creas que le haré daño. Lo soltaré una vez que lo haya examinado.

ROSALUZ.- ¿Y para qué lo vas a examinar? (Por la derecha aparece María, la esclava de Rosaluz) ¡Allí viene Maria!

MARIA.-iAve María Purísima! Han tocado por segunda vez en Los Descalzos.

SANTIAGO.-¿Vienes del río?

MARIA.-Si, Vuesa Merced. 
SANTIAGO.- ¿No has visto pasar a los pájaros?

MARIA.- ¿A los pájaros? A fe mía, no los he visto.

ROSALUZ.-Tú crees que todo el mundo está pendiente de ellos. ¡Vámonos ya!

MARIA.-Dense prisa, mis amos, que llegaremos tarde al Santísimo.

SANTIAGO.-Anda no más, que te seguimos.

MARIA.-(Saliendo) De cerquita, mis amos, que no volveré la cabeza.

SANTIAGO.-( $A$ Rosaluz, que empieza a caminar) Espera, aún no te he terminado de contar.

ROSALUZ.-( Se detiene) ¿Qué cosa?

SANTIAGO.-Lo que hay dentro de esta jaula.

ROSALUZ.-Ya me lo dijiste: hay un pájaro.

SANTIAGO.-Este pájaro es un tesoro. Ha sido un milagro cazarlo por aqui porque ellos sólo viven del lado del mar.

ROSALUZ.-Pues es una buena noticia la que me das. Podrás venderlo por muy buenos duros.

SANTIAGO._- ¿Venderlo? ¡Nadie dará por él un cuarto! Para los demás no vale nada, ni siquiera sabe cantar. Pero para mí tiene una importancia que no puedes imaginar. Lo soltaré en mi desván y observaré cómo vuela.

ROSALUZ.- $i$ En eso ocupas tus noches?

SANTIAGO.-Has adivinado.

ROSALUZ.-(Alejándose de él) ¡Pero Dios mfo!

SANTIAGO.- ¡Espera, Rosaluz!

ROSALUZ.-(Saliendo) ¡Perder su tiempo de esa manera!

SANTIAGO.-(Siguiéndola) ¿Pero no te das cuenta para qué observo a los pájaros?

(Rosaluz sale por la derecha. Santiago se Sobrepara y regresa por su jaula. Cuardo la recoge los pajaros empiezan a cantar nuevamente entre el follaje. Santiago queda observándolos un momento y avanza, la cabeza en alto, hacia las piedras, pero se escuchan las campanas de Los Descalzos. Santiago sale rd́pidamente por la derecha)

\section{TELON}




\section{CUADRO SEGUNDO}

\section{EN EL PORTAL DE BOTONEROS}

Portal de Botoneros. Siete de la noche. Santiago va de la tienda a la trastienda guardando sus jaulas. Penetra Basilio a la carrera.

\section{ESCENA PRIMERA}

BASILIO.- iEchame un poco de agua, Santiago, que llevo un incendio en el corazón!

SANTIAGO.-Pero, ¿qué sucede?

BASILIO.-iAbrázame tres veces y bésame en las dos mejillas!

SANTIAGO.-Por azar, ¿has ganado la lotería?

BASILIO.-Las loterías sólo las ganan los frailes y los familiares de la Santa Hermandad.

SANTIAGO__iTe han hecho gobernador de una provincia?

BASILIO.- ¡Jamás le he besado Gos pies a nuestro "ilustrísimo virrey! SANTIAGU.-No sé, entonces, a qué se debe tu arrebato.

BASILIO.- iEstoy enamorado!

SANTIAGO.-¿Otra vez?

BASILIO_- ¡No! Esta es la primera vez que sufro tan bello accidente.

SANTIAGO.-Dime cómo ha ocurrido eso.

BASILIO.-Estuve en el teatro y vengo transtornado, transportado, sediento...

SANTIAGO.- ¡Por Dios! ¿No será de Micaela Villegas?

BASILIO._ ¡El diablo me libre de semejante pez! Es un bocado muy grande para un humilde pecador como yo. Dicen que nuestro honradísimo y sexagenario virrey ha perdido el seso por ella y esta gastando los doblones de la corona en construirle un palacio.

SANTIAGO.-Pcro, ¿quién, entonces, te ha puesto en semejante estado? BASILIO.-¡Isabclilla!

SANTIAGO.- ¡No se quién será!

BASILIO.- ¿Es posible que no la conozcas? Claro, tú jamás te mueves 
de tu tienda sino es para ir al San Cristóbal o Amancaes a cazar pajarracos. Isabelilla es una nueva actriz.

SANTIAGO.-¿Cómo es?

BASILIO.- $i \mathrm{Y}$ crees que lo sé? ¡He estado dos horas en el teatro mirándola sin verla o viéndola sin mirarla! Necesitaría tener el ingenio de Dante para describirla. Pero mi numen de coplero ha dado sólo para un cuarteto. Escucha:

$$
\begin{aligned}
& \text { La madre que te parió } \\
& \text { mereciera parir veinte } \\
& \text { y que yo fuera diezmero } \\
& \text { y me tocaras en suerte. }
\end{aligned}
$$

(Ambos rien. Santiago queda pronto callado y pensativo).

BASILIO.-No te veo el ánimo muy alegre. Pareces un recaudador de impuestos que ha perdido su cargo. ¿Qué te sucede?

SANTIAGO.-(Suspira) Han pasado muchas cosas en estos días.

BASILIO.-Estoy seguro que es por Rosaluz por quien suspiras.

SANTIAGO.-No es por ella.

BASILIO-— iVoto al diablo! ¿Por quién ha de ser, entonces? Juraría que hoy dia no la has visto.

SANTIAGO.-Hace diez dias que no la veo.

BASILIO.- ¡He allí la razón!

SANTIAGO.-No la veo desde nuestro último paseo al San Cristóbal. He ido luego a visitarla y no la he encontrado. Pero no es esto lo que me acongoja.

BASILIO.-A mi turno, me tocará adivinar.

SANTIAGO.-No podrás adivinarlo? ha muerto mi tijereta.

BASILIO.-¿Qué eś eso?

SANTIAGO.-Un ave extraña que capturé hace poco.

BASILIO.- ¡Ya sabía que en todo esto había pájaro encerrado! Pero no te aflijas: aves hay a millares en el cielo; en todo caso, hay más aves que mujeres.

SANTIAGO.-Pero ésta es difícil de encontrar. Vuela por los mares del sur.

BASILIO.-Mira, te traeré un jilguerillo para que te consueles. Baltazar podrá birlar uno del convento de su padrino.

SANTIAGO.-No es lo mismo. Tendré que ir al Callao o a las playas de Lurin para conseguir otra semejante.

BASILIO.-Bueno, ya que no te puedo consolar, te ofrezco un vaso de vino.

SANTIAGO._¿En el "Doblón de Oro"?

BASILIO.-Sí, Baltazar nos espera alli. Lo dejé medio borracho.

SANTIAGO.-Me gustaría acompañarte, pero prefiero quedarme aqui. Necesito pensar. He tenido últimamente muchas ideas. 
BASILIO.-_¿Qué clase de ideas?

SANTIAGO.-Ideas, no sé cómo decirlo, ideas que me enceguecen. Por momentos creo volverme loco.

BASILIO.-Nunca me has hablado de esas cosas.

SANTIAGO.-Mi cabeza arde como una fragua. Algo está sucediendo aquí adentro, algo que no puedo ver con claridad, pero que sin duda será algo admirable.

BASILIO.-Pero, dime al fin en qué ocupas esa cabeza.

SANTIAGO.-Es un secreto, Basilio.

BASILIO.-iPor piedad, déjate de secretos! Yo no te oculto nada. De $\mathrm{mi}$ amor por Isabelilla pensaba hacer el único misterio de mi vida $\mathrm{y}$ no bien he salido del teatro que ya estoy aqui, pregonándolo a los cuatro vientos.

SANTIAGO.-En otra oportunidad te hablaré. Además, todavia no estoy seguro. E.s cuestión de dias o tal vez de minutos. He llegado al limite de la reflexión y la luz tiene que estallar.

(Baltazar aparece, tambaleándose, y penetra en la tienda).

BALTAZAR.-Basilio, sabia que te iba a encontrar aquí. Embózate en tu capa y sígueme.

BASILIO.-Iba en este momento al "Doblón de Oro".

BALTAZAR.-Déjate de doblones, que buena falta nos hacen. Ahora no vamos alli. Ahora nos vamos al puente.

SANTIAGO.-Por ventura, ¿sabes cuántos vinos te has bebido hoy, Baltazar?

BALTAZAR.-Por cada vino abri un agujero en la mesa y cuando me levanté la mesa parecía un cernidor. ¡Basilio, se trata de un lance de honor!

BASILIO._- ¿Un duelo, por casualidad?

BALTAZAR.-iChitón̆ r iNo havinul hombre eque use bata conmigo! (Extrae de su capa unas tijeras). ¿Sabes para qué sirve este instrumento?

BASILIO.- ¡Cuernos! ¡Con eso eres capaz de degollar al mismo Sansón! BALTAZAR.-Con toda seguridad, degollaremos algo esta noche.

SANTIAGO.-Vayan con cuidado, Basilio. $Y$ tú, Baltazar, harías mejor en regresar a tus esculturas.

BALTAZAR.-¿¿Quién dice que yo soy escultor? Lo único que hago es dar de cuchilladas a la madera o a la piedra,... también a las personas cuando se cruzan en mi camino. Apúrate, Basilio, que la persona que me interesa ya debe estar cerca del puente. (Ambos se embozan en sus capas y desaparecen por la izquierda. Santiago sale a la calzada. Pasa un vendedor de jazmines, luego un vendedor de cigarros. Santiago compra uno y luego de encenderlo queda pensativo, mirando al cielo. El barbero sale de su tienda contigua). 


\section{ESCENA SEGUNDA}

BARBERO.-Buenas noches, maese Santiago:

SANTIAGO.-(Sin dejar de mirar al cielo). Buenas noches le dé Dios. BARBERO.-iTomando el fresco?

SANTIAGO.-Contando las estrellas.

BARBERO.-Usted siempre mirando hacia arriba.

SANTIAGO.-Arriba, por lo menos, no vemos gente fastidiosa.

BARBERO.-Puede usted caer en un charco.

SANTIAGO.-Y ahogarme, ¿no es verdad? ¡Mucha gente se alegraria!

BARBERO.-Lo sentiríamos mucho, don Santiago.

SANTIAGO.-Sobre todo aquí, en los portales.

BARBERO.-(Acercándose) Hace días que no veo a Rosaluz por estos lugares.

SANTIAGO._- ¿De veras? Yo tampoco.

BARBERO.-(Acercándose más) Don Santiago, quería hablarle otra vez de ese asunto.

SANTIAGO.- ¿De qué asunto?

BARBERO.-_Por Dios, usted lo sabe bien!

SANTIAGO._- ¿De mi tienda?

BARBERO.-Justamente.

SANTIAGO.-Mi respuesta es la misma: ¡no!

BARBERO.-Le doy por el traspaso trecientas onzas de oro.

SANTIAGO.-Veo que hà subido custed la oferta.

BARBERO.-Usted sabe, maese Santiago, la falta que me hace su local. Mi clientela crece todos los días. Soy el mejor barbero de la Ciudad de los Reyes. Necesito agrandar mi negocio y abrir aquí al lado una perfumería y una farmacia.

SANTIAGO.- ¿Y qué será de mí, pobre pajarero?

BARBERO.--Usted se arruina aquí, don Santiago. Olvídese de los pájaros y ponga un camal en la calle de los Mataderos. Se lo recomiendo, es un buen negocio.

SANTIAGO.-Usted olvida una cosa, maese Gonzalves: yo no soy comerciante.

BARBERO.-(Con despecho) A veces me parece que Ud. me tiene mala fe y que no me cede su tienda solamente por perjudicarme.

SANTIAGO.- ¿Yo?

BARBERO.-(Alejándose) Ud. me tiene inquina, don Santiago. (Entra en su tienda. Santiago apaga su cigarro y penetra en su tienda. Queda pensativo detrás del mostrador. Por la derecha aparece Rosaluz det brazo del Duque de San Carlos). 
DUQUE._Estas calles del centro están muy bien iluminadas, lo cual es una desgracia para los enamorados. ¿No conoce Ud. algún sitio donde un caballero pueda pasearse con una bella moza sin despertar la envidia ni la indiscreción de las gentes? En Madrid es muy sencillo; basta caminar hasta el barrio de Atocha.

ROSALUZ.-Un hombre galante como su Señoria, no necesita de guia alguno en este país. Pronto conocerá las calles más tranquilas de la ciudad. Pero, vea usted, hemos llegado.

DUQUE.- ¡Con que ésta es la tienda de Santiago, el pajarero! (Santiago los ve y sale a saludarlos).

ROSALUZ.-Tengo el honor de presentarte al Duque de San Carlos.

SANTIAGO.-( Se inclina) Dios guarde a su Señoría.

DUUQüE.-Encontre a la simpática Rosaluz en el Paseo de Aguas y ha tenido la amabilidad de conducirme por una ciudad que apenas conozco. Hace una semana llegue de Cádiz.

SANTIAGO.-Sea usted bienvenido.

ROSALUZ.-EI Duque de San Carlos andaba buscando una barbería. Me permití recomendarle la de Esteban Gonzalves.

SANTIAGO.-Hiciste bien. Es nuestro mejor barbero.

DUQUE.-(Observando la tienda) Tiene usted un negocio muy acogedor. Yo también soy aficionado a las avecillas. (Con intención) Tal vez me anime a comprarle alguna.

SANTIAGO.-Será un placer poder servir a su Señoría.

DUQUE.-A propósito, me dijo la gentil Rosaluz que Ud. trabajo en la marina.

SANTIAGO.-Durante diez años.

DUQUE.-Yo podría hacer gestiones para que usted se reincorpore. He sido también marino en mi juventud. Bella carrera, por cierto, donde con suerte se pueden hacer buenos doblones.

ROSALUZ.-( A Santiago) El señor Duque es pariente de nuestro Virrey. DUQUE.-Eso no significa nada. Lo cierto es que me encantaría poder ayudarlo. Rosaluz dice que usted conoce muy bien la navegación. Con dos años más de práctica podría llegar a ser primer piloto. Justamente el barco en el cual vine zarpa en estos días para Panamá y luego seguirá viaje hasta España.

SANTIAGO.-Le agradezco mucho su ofrecimiento, pero no puedo aceptarlo.

DUQUE.-Piénselo bien. Por los tiempos en que vivimos, es la manera más segura de lograr fortuna. Así, no tendrá que hacer esperar más tiempo a tan linda flor, para casarse.

SANTIAGO.-Lo sé perfectamente. 
DUQUE.- $i$ Acaso no le interesa el mar?

SANTIAGO.-En estos momentos, más me interesa el cielo.

DUQUE.- ;Caramba, es usted devoto!

SANTIAGO.-Veo que no me he explicado bien.

DUQUE.-Bueno, no quiero distraerlos más tiempo. Querrá usted hablar con su gacela. La barbería está alli, ¿verdad? (A Santiago) Le deseo mucha ventura. (A Rosaluz le besa la mano) A sus pies. (Entra a la barberia).

\section{ESCENA CUARTA}

SANTIAGO._- ¿De dónde has desenterrado esa carcasa?

ROSALUZ.-(Escandalizada) ¡Santiago, ten más respeto por un Duque! Está hospedado en el palacio de Amat... ¿Sabes? Me ha pedido que le ayude a buscar su servidumbre. Necesita cuairo esclavos negros.

SANTIAGO.-Que los compre en el mercado.

ROSALUZ.-El los quiere fornidos y obedientes. Le diré a María que busque entre sus conocidos.

SANTIAGO.-¿¿Dónde está María?

ROSALUZ.-Eso mismo me pregunto yo. Hasta los portales nos venia siguiendo. Luego desapareció.

SANTIAGO.-Mejor; así podremos hablar tranquilamente. Para empezar, ¿a qué debo el honor de esta visita?

ROSALUZ.- $i$ Te sorprende que venga a visitarte?

SANTIAGO.-Hace diez dias que no te veo.

ROSALUZ.-Estuve enferma.

SANTIAGO.-Sin embargo, estuvistelen la peleasde, gallos.

ROSALUZ.- ¿Cómo lo sabes?

SANTIAGO.-No olvides que soy pajarero. Tengo un jilguerillo que me cuenta todo.

ROSALUZ.-Dirás mejor, un Gavilán. Ese borrachín te ha venido con chismeş.

SANTIAGO.-No hables mal de Baltazar... (Con vehemencia). Rosaluz, créemelo, te he extrañado mucho en estos días.

ROSALUZ.-Yo también, Santiago... Tú sabes que te quięro, a pesar de todo.

SANTIAGO.- ¿Por qué dices, "a pesar de todo"?

ROSALUZ.- ¡Porque eres el hombre más tonto que pisa la Ciudad de los Reyes! Imagínate, rechazar uni oferta ccmo la que te ila hecho el Duque de San Carlos, para reingresar en la marina. Cuanclo dijiste: "no", estuve a punto de saltarte al cuello y arañarte.

SANTIAGO.- ¿Quieres, acaso, que me vaya de Lima?

ROSALUZ.- ¡No es eso!

SANTIAGO.- ¿Qué quieres que haga, entonces? 
ROSALUZ.-Que te establezcas, que hagas algo útil; en fin, que hagas algo de lo cual pueda sentirme orgullosa.

SANTIAGO.-Haré algo de lo cual todo el mundo hablará.

ROSALUZ.- ¡Déjate de quimeras! Tú vives en las nubes. De proyectos, estoy cansada.

SANTIAGO.-Pero si tú no tienes fe en mi, ¿quién la tendrá?

ROSALUZ.- iYo no puedo ser eternamente la novia de Santiago, el Pajarero!

SANTIAGO.-Ten un poco de paciencia.

ROSALUZ.-Me duele decirlo, pero tengo que hacerlo. He conversado con mi mamá sobre tu porvenir. Ella también está perdiendo la paciencia.

SANTIAGO.- ¿Qué tiene que ver tu madre en todo esto?

ROSALUZ.-Quiere que te fije un plazo. Nuestros amores duran ya cuatro años. La gente comienza a murmurar.

SANTIAGO.-Un plazo... ¿para qué?

ROSALUZ.- $i$ No te digo que vives en las nubes, Santiago? ¿Para qué ha de ser? Para que te decidas.

SANTIAGO.-Yo estoy decidido.

ROSALUZ.-iVeo que no me entiendes! Se trata de que en este plizo hagas algo; que al cabo de un tiempo, me digas: "Fíjate, cuento con todo csto, podemos señalar ya la fecha de nuestro casamiento".

SANTIAGO.- ¿Y cuál sería ese plazo?

ROSALUZ.-No sé... pongamos un mes.

SANTIAGO.- iUn mes!... Pero, ¿te das cuenta de lo que dices? En un mes no hay tiempo ni para soñar. Un mes pasa como un relámpago o como un escalofrio.

ROSALUZ._ ¡Debes hacer un esfuerzo!

SANTIAGO.-Un esfuerzo, ¿dices?... (Reflexivo)" Quizás tengas razón... En estos días todo puede suceder... ifaltan tan pocos detalles!... Rosaluz, ¡valga el plazo! En un mes sabré a qué atenerme. ROSALUZ.-(Abrazándolo) ¡Bravo, Santiago!... Pero, ¿me lo prometes seriamente?

SANTIAGO.-Seriamente, Rosaluz.

ROSALUZ.- ¡Mi madre se pondrá contenta!... ¿Y qué cosa harás en este mes? ¿Venderás tu tienda?

SANTIAGO.-No sé...

ROSALUZ.-¿Entrarás en la marina?

SANTIAGO.-No sé, no sé, Rosaluz... no me preguntes nada. Déjalo todo por mi cuenta. Lo único que te digo es que haré algo importante.

ROSALUZ.- ¡Será una gran sorpresa para mi!

MARIA.-(Aparece sofocada, con un ramillete de jazmines en la mano) ¡Ave María Purísima! Buscando al jazminero por toda la ciudad.

Lo encontré en la calle del Gato, cerca de la farmacia.

SANTIAGO-(Mirando el ramillete) ¿Dc dónde has sacado eso? 
ROSALUZ.-iQué lindo ramillete!

MARIA.-El señor Duque me pidió en secreto que lo comprara.

ROSALUZ.-(Cogiéndolo) ¿Es para mí?

MARIA.-Debe usted ponérselo en el pelo. A la derecha, como lo usan las mujeres solteras.

(Rosaluz se lo pone)

SANTIAGO.-Si todo marcha bien, pronto lo usarás a la izquierda.

ROSALUZ.-El duque es muy gentil.

SANTIAGO.-Debía estar celoso, pero esta noche me siento particularmente fuerte; no me asustan los duques ni los virreyes.

ROSALUZ.-Bien, Santiago, te dejamos solo. (Lo besa con ligereza).

MARIA.-(Mientras sale) Por la Catedral vi pasar a su amigo Basilio Iba corriendo y su capa flotaba; parecía un cóndor.

SANTIAGO.-(Interesado) ¿Cómo dices?

MARIA.-Que corría como alma que lleva el diablo.

SANTIAGO._ ¡No! Algo más dijiste.

MARIA.-Que parecía volar, como un cóndor.

SANTIAGO.- ¡Como un cóndor! Eso es... ¿y dices que su capa flotaba?

MARIA.-Sobre sus hombros.

SANTIAGO.-Volaba como un cóndor.

ROSALUZ.-(Saliendo) Hasta pronto, Santiago. Y acuérdate de lo prometido. Deja a un lado las quimeras y pórtate bien. (Desaparece con Maria por la izquierda. Santiago queda ensimismado. Luego comienza a pasearse por su tienda, excitado).

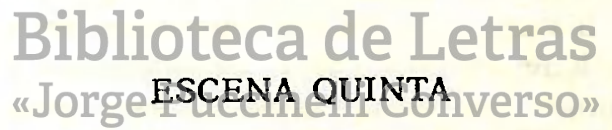

BASILIO.-(Aparece corriendo). ¡Escóndeme, Santiago, que me persiguen los alguaciles!

SANTIAGO.-(Sin inmutarse) Me dicen que volabas, como un cóndor.

BASILIO.- ¡Por amor de Dios! ¿Quieres verme ahorcado en la Placa Mayor?

SANTIAGO.-No hablemos de esas cosas, hay algo más importante. (Se escuchan pasos precipitados).

BASILIO.- ¡Ya están aquí! (Desaparece por la trastienda. Dos alguaciciles se detienen en la puerta de Santiago).

ALGUACIL I.- ¿Ha visto pasar a un hombre embozado en una capa? SANTIAGO.-No me pregunten nada

ALGUACIL I.- ¿No reconoce nuestros distintivos? Somos los alguaciles de la villa.

SANTIAGO.-Sigan buscando. Con paciencia todo se encuentra.

ALGUACIL I.-(Al alguacil II). Este hombre está enajenado. (Siguen su camino). 
BASILIO.-(Aparece por la trastienda) ¿Se fueron ya?

SANTIAGO.-Estoy obcecado, Basilio, perdóname... (Se golpea la frente). Esta cabeza anda mal... ¿Has cometido aigún crimen?

BASILIO.-Ha sido Baltazar.

SANTIAGO.-iVamos! ¿Qué cosa ha hecho ese demonio?

BASILIO.-Déjame que te cuente. Salimos de aquí juntos, ¿recuerdas? Cuando llegamos al puente, Baltazar me dijo: "No te muevas de aquí. Cuando veas pasar a la mujer que te indicaré, te acercarás a ella y le preguntarás cualquier cosa". Baltazar se apoyó en la baranda y y yo quedé esperando su señal. "Alli viene", me dijo de pronto. Era una mujer que tú, yo y todo Lima conoce porque Baltazar hace tres años que enloquece por ella.

SANTIAGO.-iMariquita!

BASILIO.-La misma. Cuando estuvo cerca, me adelanté y le pregunté: "¿Dónde venden la gallina de los huevos de oro?"... Baltazar que estaba agazapado, saltó a sus espaldas con la tijera en la mano...

SANTIAGO.—iLa mató!

BASILIO.-Algo peor: cortó la trenza de un solo tijeretazo, saltó el vellocino ençantado,... La bella gritó,... Dos alguaciles remontaban el puente. ¡Ya podrás imaginarte!... Baltazar salió disparado hacia el Rastro de San Francisco y yo volé hacia la Catedral.

SANTIAGO.- ¿Lo habrán cogido?

BASILIO.-El es más ágil que yo y se dio maña para despistarlos. Fue a mi a quien persiguieron.

SANTIAGO.- iEsa historia merece un buen vaso de vino!

A Mariquita la llamarán, de ahora en adelante, Mariquita La Pelona... ¡Yo también me siento elifórico vesta noche!

BASILIO.-Lo noto. ¿Vino Rosaluz?

SANTIAGO._ ¡ $\mathrm{Ha}$ venido hasta un Duque a visitar mi pocilga!... Pero no es eso lo que me tiene transtornado. Basilio: creo que te voy a revelar un gran secreto.

BASILIO.- ¡Vamos!, échalo de una vez.

SANTIAGO.-Pero no sé cómo explicarlo, ni por dónde comenzar.

BASILIO.-Comienza por el fin, si te es más fácil.

SANTIAGO.- ¿Tú sabes por que vuelan los pájaros?

BASILIO._ ¡Por Judas Iscariote! ¡Sabía que me ibas a salir con una de esas historias!

SANTIAGO.-Esta vez hablo en serio. Es un asunto tan grave que en él va mi salud, y no solamente la mía.

BASILIO.-Me asustas, Santiago.

SANTIAGO.-Repito: ¿Sabes tú por qué vuelan los pájaros?

BASILIO.-Porque tienen alas, me imagino.

SANTIAGO.-Es una respuesta muy simple... ¿Ves esta hoja de pa- 
pel? (La coge y la arruga). Si yo hago una bola con ella y la dejo caer (la suelta), el papel caerá directamente al suelo.

BASILIO.-Así veo.

SANTIAGO.-En cambio, si a esta otra (coge otra), le doy otra forma (la dobla suavemente por la mitad), y la suelto, a pesar de ser igual a la primera y tener el mismo peso, se mantendrá un momento en el aire. (Deja caer la hoja).

BASILIO.-Naturalmente.

SANTIAGO.-Todo consiste en encontrar una forma tan perfecta que los objetos se mantengan en el aire en lugar de precipitarse.

BASILIO.- $i \mathrm{Y}$ cuál es esa forma?

SANTIAGO.-La forma ya la he encontrado. Lo que falta es el impulso. BASILIO.-Pero, $\subset$ adónde te llevará todo esto?

SANTIAGO.-A una sola cosa: el hombre puede volar.

BASILIO.-(Cogiéndose la cabeza) ¡Pero, Santiago! ¡Estás loco! Deberías hacerte exorcizar.

SANTIAGO.-No en vano he estudiado a los pájaros durante diez años. $\mathrm{He}$ hecho y roto cientos de díseños. Mi desván guarda los rastros de todos mis proyectos. Pero el diseño que ahora tengo en mente no me pucda fallar. Basilio: se trata de un gran invento.

BASILIO.-No te creo una palabra, Santiago, pero me entusiasmas. Además, todo es posible en esta miserable creación.

SANTIAGO.- $¿$ Te imaginas, Basilio, al hombre atravesando los espacios? ¿Volando a la velocidad del cóndor? Un día bastará para llegar a Panamá. Se podrá atravesar los mares más rápido que las carabelas. En tres etapas se llegará a la Metrópoli: ¡Un día hasta Portobelo, otro hasta la Habana y otro hasta Madrid! ¡Es posible, Basilio, es posible!

BASILIO._-iSi aquello resulta te llamarán Santiago, el Volador!

SANTIAGO.-De aquí a un mes terminaré mi último diseño. Me falta examinar algunos tipos de aves, un cóndor, entre otros. Luego escribirć una memoria y la presentaré al Virrey. ¡Mi invento será una revolución!

BASILIO.-Si Amat te recibe, estás salvado. ¡Te volverás rico!

SANTIAGO.-Eso vendrá por añadidura. Lo importante es superar a las aves, conquistar el aire y darle al hombre el dominio total del universo.

BASILIO.-_ ¡Bravo, Santiago, hablas como un poeta! Ahora soy yo quien te ofrece un vaso de vino.

SANTIAGO.-Esta vez, creo habérmelo ganado con todo derecho. (Apaga el quinqué y coge su capa). Vamos a buscar a Baltazar para bebernos unas copas en el "Doblón de Oro" (Cierra la puerta. Ambos se cogen del brazo y mientras se retiran de la escena, Basilio va cantando la copla de Santiago el volador). 
Santiago, de pajarero

Se convirtió en inventor,

Ya no le pidan romero

Para el pájaro cantor.

Santiago, dice el coplcro,

Gana el cielo con primor.

Desde hoy, mi compañero

¡Es Santiago el Volador!

TELON

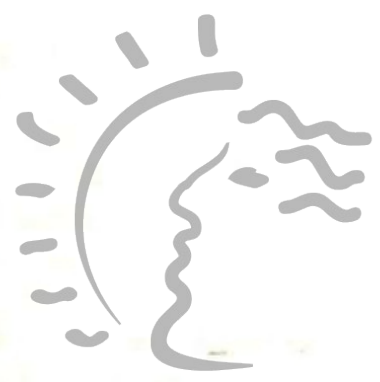

Biblioteca de Letras

"Jorge Puccinelli Converso» 


\section{CUADRO TERCERO}

\section{EN EL PALACIO DEL VIRREY AMAT}

AMAT.-(Entrando, a su secretario) ¿Quién es ese hombre?

SECRET.-Santiago de Cárdenas, su Excelencia.

AMAT.-Sí, pero, ¿quién es?

SECRET.-Hace quince clias que solicita una audiencia de Usia.

AMAT.- ¿Es contribuyente? ¿Tiene algún oficio?

SECRET.-Es pajarero.

AMAT.- ¿Y para qué lo dejan entrar?

SECRET.-Ha inventado algo, no sé exactamente qué. Además, el Duque de San Carlos to ha recomendado.

AMAT_-_EI Duque de San Carlos! Debe de haber de por medio un asunto de faldas. Que se acerque. (Llega al sillón).

SANTIAGO.-(Profunda inclinación). A los pies de su excelencia.

AMAT.-(A Santiago). Sea breve (A su secretario). ¿Ha llegado ml barbero?

SECRET.-(Desolado):gSuP excelenciaj. Unanmanueva. Su barbero ha sufrido un accidente.

AMAT._-iTengo que ir a comer a Miraflores, a casa de mi primo Amat de Ricoberti! ¿Qué cosa voy a hacer?

SECRET.-Hemos encargado que consigan un reemplazo.

AMAT.-A buena hora. (A Santiago) ¿Decia usted?

SANTIAGO.-Soy Santiago de Cárdenas, Pajarero de oficio, ex-grumete de la Marina Real e inventor por vocación y temperamento.

AMAT.-(Al Secretario) Hermosa colección de títulos. (A Santiago) Continúe Ud.

SANTIAGO.-He escrito una Memoria de 270 páginas que presento a consideración de su Excelencia. (Extiende el grueso manuscrito).

AMAT.-(Sin cogerlo) ¿Y iqué quiere usted que haga con eso? ¿Que lo lea? Mi vista anda muy mal por estos tiempos y no leo sino las cosas que me entretienen.

SANTIAGO-Le aseguro a su Excelencia que su lectura será sumamente ilustrativa. 
AMAT.- ¿De qué se trata?

SANTIAGO.-Del arte de volar.

AMAT.-(Al Secretario). Este hombre está loco. (A Santiago) ¿De volar decía usted? ¿Por los aires? (Imita con su mano al vuelo de una mariposa). ¿Así?

SANTIAGO.-De volar en un aparato de mi invención.

AMAT.-(Coge el manuscrito) ¡Y ello está contenido aquí!

SANTIAGO.-Con todo lujo de detalles. (Ruido en la puerta de la izizquierda. Voces confusas).

AMAT.-( A Santiago. Entregándole el manuscrito). Tenga un momento. (Al secretario). Le he advertido mil veces que no tolero inte. rrupciones. ¿Quć batahola es esa? ¡Que no me interrumpan!

SECRET.-Salgo en este momento a ver. (Sale por la izquierda).

AMAT.-Succde que mi alto cargo se encuentra siempre bajo la amenaza de imprevistos asuntos de Estado. Los Gobernadores, los Corregidores, los Oidores me asaltan sin interrumpción y no mc dejan un momento de reposo. Continúe Ud. que lo escucho con suma atención. (Vuelve el secretario). ¿Y qué hay de ese barbero quc todavía no aparece?

SANTIAGO.-Decia a su Excelencia que después de diez años de estudios he logrado diseñar un aparato que pueda transportar al hombre por los aires.

AMAT.-(Distraido). Y dígame usted... ¿Cuál es su nombrc?

SANTIAGO.-Santiago de Cárdenas, su Excelencia.

AMAT.-De Cárdenas, sí, sí... ¿un aparato, decía Ud....?

SANTIAGO.-Para volar por los aires.

AMAT._- Válgame Dios! ¿Y eso es posible?

SANTIAGO.-Puedo argumentarnsi le le place assu Excelencia.

AMAT.—iPor favor, nada de argumentaciones!

SANTIAGO-Si pudiera usted leer mi memoria y lucgo prestarme la ayuda suficiente para construir $\mathrm{mi}$ ingenioso instrumento...

AMAT.-(Sobresaltado) ¿Ayuda, dice usted?

(Por la derecha, aparece el secretario seguido del barbero que trae sus implementos en una bolsa).

SECRET.-EI barbero Esteban Gonzalves.

BARBERO.-(Profunda inclinación). Es un alto honor para mí poder servir a nuestro excelentisimo Virrey.

AMAT.-(Al barbero) ¡Ya está usted aqui! ¿Seria capaz de despacharme en cinco minutos? (Saca su reloj). Tengo una reunión importante. Si se expide Ud. con fineza, lo recompensaré debidamente.

BARBERO.-A las órdenes de su Excelencia. ¿Cómo quiere que le haga la barba?

AMAT.-Sin chistar. (Al secretario) Que no se reciba una persona más esta mañana. Remita para otra ocasión las audiencias pendientes. (El secretario sale por la derecha mientras el barbero extrae de su 
bolsa una jabonera, una brocha, una navaja y un mandilillo blanco con el gue cubre al Virrey como lo hacen los peluqueros de hoy y comienza su trabajo. Amat a Santiago:) Lo escucho, señor de Cár. denas. (El barbero, al percibir la presencia de Santiago, deja caer su brocha). ¿Así empieza usted su trabajo?

BARBERO.-Mil perdones, Excelentísimo señor. (Recoge la brocha y jabona la cara del Virrey).

SANTIAGO.-Su excelencia sabrá que el trabajo del inventor es muy sacrificado. He consumido toda mi bolsa en estudiar y llevar a cabo mi proyecto. Confío por lo tanto en que mi Memoria merecerá la atención de su Excelencia y la ayuda de la corona.

AMAT.-(Al barbero). No me vuele usted las patillas. (A Santiago). Naturalmente. Pero antes de tomar una determinación... (El Duque de San Carlos ingresa por la puerta de la derecha)... No lo esperaba tan temprano, señor Duque. ¡Qué gratísima sorpresa! DUQUE.-Como el asunto atañía directamente a su Excelencia me he preocupado en informarlo con prontitud. (Distinguiendo a Santiago). Veo que atiende usted a mi recomendado.

AMAT.- ¿A su recomendado? En efecto me está contando cosas muy divertidas. Bueno, ¿y a qué conclusiones ha llegado usted?

DUQUE.-(Confidencial, sacando unos papeles). ¿Es necesario suje. tarse a los planos y presupuestos del arquitecto Torrella?

AMAT.-Sin duda alguna. Quiero que este teatro sea un primor. Desde hace años abrigo la esperanza de tener un teatro en mi propio palacio para el uso exclusivo de mis actores preferidos.

DUQUE.-La verdad es que las arcas del Virreynato se encuentran un poco exhaustas y no veo la forma de financiar una construcción tan lujosa.

AMAT.-Pero, mi querido Duque, por algo es usted experto en finanzas y enviado especial de la Metrópoli. Hay que ver la forma de aumentar los ingresos.

DUQUE.-La única forma es creando nuevas contribuciones.

AMAT.-Cree usted todas las que juzgue convenientes. Pero eso sí, procure no gravar a la gente de sangre. Aquello siempre ocasiona dolores de cabeza.

DUQUE.-Gravaremos a la Iglesia.

AMAT.-En todo caso, no toque usted al alto clero. Limítese a los curas provinciales.

DUQUE.- ¿Y a los comerciantes?

AMAT.-Con ellos hay que proceder cautelosamente. Suprímales unos gravámenes y créeles otros nuevos, de modo que a la postre resulten dando más de lo que ahorran.

DUQUE.- $i Y$ al pueblo?

AMAT.- ¡Oh, por él no se preocupe! Mi querido pueblo resiste todo. 
Le daremos espectáculos y algún buen escándalo que entretenga sus pasiones $y$ apacigue su humor.

DUQUE.-Pues si usted me da carta blanca en estos asuntos, le aseguro que su teatro será financiado con creces.

AMAT.-Enhorabuena, mi querido Duque. $Y$ disculpe Ud. que lo haya recibido en este atuendo.

DUQUE.-La semana próxima tendré listo mi nuevo plan de impuestos. (Hace una reverencia y se retira por la derecha).

AMAT.-(Suspira). Oficio delicado es gobernar tierrás tan grandes como incultas. Han pasado cinco minutos y aún no me quita de la cara esta lavasa.

BARBERO.-En cl acto, Excelentísimo señor.

AMAT_-(A Santiago) Prosiga usted, señor de... ¿Cómo me dijo?

SANTIAGO.-Dc Cárdenas, su Excelencia.

AMAT.-Me hablaba usted de...

SANTIAGO.-De un aparato volador cuyos detalles constan en esa Me. moria.

AMAT-iPero se da usted cuenta exactamente de lo que dice?

SANTIAGO.-Su Excelencia, quienes me conocen pueden testimoniar de mi absoluta seriedad y $\mathrm{mi}$ buen juicio (El barbero tose).

AMAT._- Qué le sucede?

BARBERO.-Disculpe, su Excelencia, pero sucede que desde hace quince años soy vecino del señor de Cárdenas.

AMAT.-Interesante referencia.

BARBERO.-Puedo testimoniar que el señor de Cárdenas es una persona honorable que se dedica a criar pájaros.

AMAT.- ¿Sabía usted que craeinventor?

BARBERO.-Confieso humildemonte que lo ignoraba.

AMAT_- ¿Es posible, señor de Cárdenas? ¡Es usted" entonces, un inventor desconocido! ¡Jamás se ha visto un caso semejante! ¿Qué títulos ostenta usted para dedicarse a esa clase de trabajos?

SANTIAGO.-No ostento otros títulos que mi talento, y mis trabajos los he realizado siempre en medio del mayor secreto.

AMAT.-Su respuesta no me satisface, ¿No será su invento una patraña para llegar a mí y pedirme alguna sinccura? Será tal vez mejor que haga usted antes méritos suficientes para aspirar a una audiencia del Virrey. Además, su Memoria tiene un formato intimidante. Yo no estoy en la edad de leer. Yo releo.

SANTIAGO.-Pero, su Excelencia, permitame...

AMAT.-(Al barbero). ¿Terminó usted?

BARBERO.-En el acto, su Excelencia. (Le quita el mandil y le presenta un espejo para que se mire).

AMAT.-(Observándose). No está del todo mal. Tiene usted ingenio para su oficio. Déjcle a mi secretario una tarjeta con sus señas per- 
sonales. Pronto tendrá noticias mías. (El barbero comienza a guardar sus utensilios en su bolsa. Amat a Santiago:) Vamos, señor, todavía sigue usted allí?

SANTIAGO.-Esperando la decisión de su Excelencia.

AMAT.-(Se levanta). Admiro su constancia, señor de Cárdenas. Pero usted mismo es testigo de que pese a mi buena voluntad no he teniclo ticmpo de ocuparme de usted como lo merece. Haria usted bien en regresar en otra ocasión. (Desciende del estrado).

BARBERO.-(Que ha guardado sus utensilios). Beso los pies de su Señoría y declaro que ha sido para mí un altísimo honor el haber puesto mi arte a su servicio.

AMAT.-Vaya usted con Dios. (Sale el varbero. Amat al Secretario). Vea usted si está lista mi carroza. (Comienza a caminar hacia la puerta de la izquierda).

SANTIAGO.-(Lo persigue). Su Excelenecia, permítame insistir. Lo que esta Memoria contiene es el fruto de diez años de trabajo. Han sido diez años extremadamente duros y que he soportado con ejemplar paciencia. Pero ahora veo que tanto más difícil que crear algo, es merecer la atención de los podcrosos. El talento inspira siempre recelo. Yo no pretendo, además, ninguna distinción ni beneficio.

AMAT.-(Impaciente). Pero, en suma, ¿qué cosa es lo que pretende usted?

SANTIAGO.-Que su Excelencia se digne echar una mirada a mi Memoria. (Extiende el mantscrito).

AMAT.-(Sin cogerlo). ¡Un aparato volador! Bonito trabajo van a tener mis profesores. (Al Secretario que vuelve) Reciba usted esta Memoria $\mathrm{y}$ hágala llegar a nuestro primer matemático don Cosme Bueno y Larrazábág parà Qquelel presenten sulinforme. (A Santiago) Está usted servido. (Sale por la puerta de la izquierda).

\section{TELON}




\section{CUADRO CUARTO}

\section{INFORME DE DON COSME BUENO}

Salón de Actos de la Universidad de San Marcos. A la derecha, perpendiculamente al escenario, larga mesa verde destinada al Cuer. po Docente. Al fondo, sienpre a la derecha, iriouna para el orador. At centro, galerias para el público. Puerta a la izquierda.

Al levantarse el telon la parte alta de las galerias se encuentra ocupada por el publico. Sigue llegando gente.

UN HOMBRE.-( $A$ su vecino). ¿Qué va a suceder aqui?

VECINO.- $i$ No lo sabe usted? $\mathrm{Va}$ a informar don Cosme Bueno.

UN HOMBRE.- ¿Sobre qué cosa?

VECINO.-Eso nadie lo sabe, ni tampoco interesa. Es suficiente con el discurso de sabio tan ilustre.

UN HOMBRE.-(Señalando). EI Duque de San Carlos. (Aparece por la derecha el Duque de San Cálos acompañadó de Rosaluz y se empla. zan en la primera fila de la galería).

VECINO-_Hola! Y "ant tenemos a Santiago. ¿Quéc cosa querrá aquí este pajarero?

UN HOMBRE,-He oido decir que ha inventado algo.

DUOUE.-(A Rosaluz). Su novio está tan nervioso que ni siquiera nos ha visto.

ROSALUZ.-Yo también me encuentro muy nerviosa, señor Duque. Preferiría no haber venido.

DUQUE,-Ya le he advertido que esta ceremonia constituirá una gran sorpresa para usted. (Por la derecha aparece el Cuerpo Docente compuesto por cinco miembros que llevan togas y cintas en el pecho. Avanzan con grave teoria y se acomodan en la mesa verde. Pausa. Expectativa. Los viejos miran hacia atrás como esperando la llegada de alguien).

Murmullos en el público: "Allí está don Cosme Bueno!" (Por la derecha aparecerá un hombre gordo, pequeño y calvo, cargado de grue. sos tibros y mantuscritos. Se dirigira sonriente hacia la tribuna y se emplazara en ella. Pausa). 
COSME B.-Ilustrísimos señores profesores de la Real y Pontificia Universidad Mayor de San Marcos. (Al Duque) Excelentísimo representante de nuestro Virrey. (A Santiago) Señor. (Pausa). Henos aquí reunidos en esta Magna Asamblea para dar lectura al informe que luego de laborioso estudio he redactado sobre la Memoria presentada por Santiago de Cárdenas, pajarero, acerca de un nuevo sistema de navegación por los aires.

(En el público, murmullos $y$ exclamaciones de sorpresa).

DIRECTOR DEL CUERPO DOCENTE.-(Agitando la campanilla). iSilencio! (A Cosme). Prosiga usted.

COSME B.-(Agitando el Manuscrito de Santiago). Esta voluminosa Memoria de 270 páginas y 16 dibujos contiene una invención, según la cual, al hombre le sería posible dominar el aire como las aves $y$ atravesar grandes espacios venciendo las leyes de la gravitación. Confieso que en mi larga vida de matemático y físico no he encontrado proyecto de suyo tan difícil y novedoso. No escapa, pues, al criterio de mi ilustrísimo auditorio la necesidad de examinar con atención los pormenores de esta teoría. (Coge el manuscrito de su informe) He dividido mi trabajo en dos partes: la primera versa sobre las objeciones teóricas al arte de volar. A la primera objeción teórica la llamo objeción de las alas infinitas. El señor de Cárcienas afirma que para que un hombre se sostenga en el aire basta dotarlo de un sistema de alas fabricadas de un material liviano. Estas alas, debido a su gran superficie, tendrían por objeto, ofrecer resistencia a la fuerza de la gravedad e impedir la caida del cuerpo volátil. Ahora bien, por livianas que sean, estas alas, tienen un peso, y para que ese peso no origine latcaída, será hecesario colocar otras alas para las alas. Pero a su vez, este nuevo juego de alas, que también pe$\mathrm{sa}$, requerirá "otrog juego denalas quellas sostenga y este a su vez otro y asi indefinidamente. De este modo, el ingerio volador del señor de Cárdenas, será un encadenamiento infinito de alas. (Santiago levanta la mano para responder, pero el Director del Cuerpo Docente le indica que se calle).

DIRECTOR.-No ha llegado su turno, señor de Cárdenas.

COSME B.-Segunda objeción, llamada objeción del cerro de aire. Los observadores de las grandes aves, entre otros, el Abate de Pluchet, en el tomo sétimo de su Espectáculo de la Naturaleza, sostiene que los grandes pájaros, para levantar el vuelo necesitan correr y al mismo tiempo ir moviendo las alas de tal manera que vayan acumulando delante suyo masas de aire, masas que van formando un cerro sobre el cual se suben hasta alcanzar el espacio. (Movimiento de aprobación en el Cuerpo Docente). Ahora bien, al horrbre le seria imposible correr y al mismo tiempo agitar las alas mecánicas y ergo, no pudiendo formar el cerro de aire, su vuelo será imposible. 
UN HOMBRE-Eh, inventor, ¿por qué no te dedicas a fabricar som breros? (risas).

COSME B.-La objeción tercera... carece de nombre. Me ha side sugerida por uno de los sabios anatomistas del Cuerpo Docente de esta Universidad, a quien agradecemos sus utilísimos servicios. El secreto del vuelo de las aves reside en que las aves carecen de hiel. SANTIAGO-(Se levanta). 'Protesto! (A Cosme Bueno) iA cuintas aves ha anatomizado Ud? Yo he pasado $\mathrm{mi}$ vida ocupado en estos trabajos y puedo asegurar que todas las aves tienen hicl. Pero aún si no la tuvieran, el detalle carece de interés. Yo no trato de darle al hombre los atributos internos de las aves sino tan sólo sus atributos externos.

UN HOMBRE.--jQute se calle!

DIRECTOR.-(A Samtiago). Debe Ud. esperar que el Catedrático de Prima de Matemáticas termine su informe.

COSME B.-Cuarta objeción, titulada objeción del silencio de los filósofos. Ni Arístóteles, ni Platón, ni Plotino, ni Santo Tomás, ni Duns Scoto, ni el Reverendo Padre Bernandino de la Orden Carmelita, se ocupan en sus sapientes tratados de la posibilidacl en el arte de volar. Toda nuestra ciencia está dontenicla en los filósofos de la antigiedad. Nosotros no somos más que humildes glosaclores dedicados a comentar e interpretar los textos inmortales. Ouien intente salirse de este senclero se precipitará de las nubes de sus quimeras en el abismo del error. (Aplausos, Cosme Bueno prosigue). Quinta objeción, llamada objeción de la armonía de la naturaleza. (Pausa). Dios Creador ha distribuido los seres de tal manera y perfección que unos, Alos peces, atenend el dominioldel mar; otros, las aves, el dominio del ciclo y al hombre pertenece el dominio de la tierra. Si Dios Creadoo hubiera querido dar al hombre el dominio del aire lo hubiera dotado de alas. Dentro cle su Omnipotencia Divina aquello era posible.

SANTIAGO-DIntermmpiendo) ¡Protesto! (A Cosme Bueno) ¿Preten. derá Vuesa Merced que el hombre no tiene el dominio del mar? ¿Como nos trasladamos de aquí a la Metrópoli si no a través de los océanos? iY para ello no ha sido necesario que al hombie Ie salgan agallas! Ha sido suficiente inventar los bajeles y las carabelas. (El Director agita su campanilla. Santiago se sienta).

COSME B.-El señor inventor, ignora, tal vez, que me encuentro en la parte teórica cle mi discurso.

UN HOMBRE.- ¿Santiago se encuentra en las nubes!

VECINO._Baja volando, Santiago!

DIRECTOR.-iOrden, señores! (A Cosme) Continúe haciendo uso de la palabra, ilustre profesor.

COSME B.-Sexta objeción, llamada, objeción teológica. La invención del señor de Cárdenas tiene un marcado sabor herético y sin duda 
altamente pecaminoso. En un pasaje de las Sagradas Escrituras, encontramos Ia siguiente sentencia: "El hombre ha sido creado para trabajar". Si el hombre se ocupa de remontar los aires desvirtúa los designios del Todopoderoso, quien lo he creado exclusivamente para el trabajo. Tenemos, en la antigüedad el caso de Icaro...

SANTIAGO. $-i \mathrm{Y}$ crce usted, señor catedrático, que volar no es un trabajo? Es uno de los trabajos más serios y difíciles a los que se puede aplicar el hombre. Tan difícil y serio es que nadie ha osado emprenderlo y quienes lo han osado...

UN HOMBRE.-iQue se calle!

DIRECTOR.Por tercera vez, señor de Cárdenas, le ruego que no interrumpa. A la próxima nos veremos obligados a suspender esta Magna Asamblea. (A Cosme) Prosiga Ud., ilustrísimo doctor.

COSME B.--Quienes han osado volar, justamente, como Icaro, se precipitaron desde los aires y perecieron victimas de sus quimeras. En este mito debemos ver una enseñanza. El Todopoderoso lo castig6 por tratar de escaparse a su condición de criatura terrestre. Icaro quiso hacer lo que al hombre le está por ley natural y divina negato. Compararse a los ángeles, arcángeles, serafines y querubines. Dios se opone al vuelo de los hambres y pretender lo contrario es no solamente absurdo sino herético. (Pausa larga).

ROSALUZ.-(Al Duque) ¿Cómo se atreve Santiago a enfrentarse a tales eminencias?

DUQUE.-(Risueño) Santiago el pajarero es muy ingenioso.

ROSALUZ.-Yo Io veo rídiculo. No debe de estar en sus cabales.

COSME B.-Señores: Nos ocuparemos ahora de las abjeciones de orden práctico Senores, les pido e Úds que hagan un desmesurado esfuerzo de imaginación y que se representen al hombre atravesando los aires "en un ingenfoso instrumento. SAdmitamos que aquello sea posible. ¿Qué cosa sucedería? Después de larga reflexión he llegado a la conclusión de que sucederian cuatro cosas, es decir, cuatro accidentes inevitables. Primero: el aparato volador sería inmediatamente atacado por las otras aves. ¿Se imaginan ustedes la reacción de las águilas, cóndores, halcones al ver invadido su dominio por organismo volátil desconocido? Estas grandes aves agresivas y carnivoras se ubatirian sobre el ingenio volador y lo derribarían a tierra. Esto' $y$ seguro que el señor de Cárdenas no ha considerado esta eventualidad. (Pausa). Pero existe un segundo peligro. Al atravesar los montes y quebradas y las selvas, como pretende nuestro inventor, para llegar hasta Portobelo, los nativos de aquellas regiones incultas $\mathrm{y}$ aún los cristianos inadvertidos, lanzarian saetas contra el ingenio voladar y tiros de arcabuz hasta derribarlo. Y si por milagro o buena fortuna el ingenio volador saliera ileso de esta travesía, tendria aún que atravesar los mares pa. ra llegar a la Metrópoli. Pcro sin duda alguna, al volar sobre el al- 
to mar sería absorbido por el piélago, como sucede con las aves que se aventuran lejos de la costa o con los barcos que van a la deriva. (Pausa). En fin, un último y más grave accidente puede sobrevenir. No ignoran ustedes que las alturas del aire están más expuestas a los calores de la luz solar que la tierra firme. Si se sobrepasa cierta altura se corre el riesgo de las quemaduras. El ingenio volador del señor de Cárdenas sería inevitablemente consumido por el fuego. Caería al suelo entre grandes llamaradas y este fiilal apoteósico sería la mejor prueba del carácter infernal y monstruoso de tal invención.

VECINO.-iQue saquen de aquí al Pajarero!

DIRECTOR.-(Campanilla). ¡Pido calma, ilustre público! El profesor don Cosme Bueno aún no ha terminado su exposición.

COSME B.-No quiero dilatar más este discurso. Me parece que ha quedado suficientemente demostrado, con ejemplos y argumentos, ei carácter irracional de la memoria presentada por el señor de Cárdenas. Quiero agradecer a nuestro ilustrisimo Virrey quien ha encomendado a mis pobres luces la refutación de tan peregrina teoría y a mis leales colegas, (Señala al cuerpo docente, uno de cuyos miembros se ha quedado dormido) cuya comprension y estimulo me han alentado en todo momento. Una vez más, esta ilustre Casa de Estudios, pozo de ciencia y de saber, sale en nombre de la verdad, para refutar a los advenedizos y audaces sostenedores de nuevas tcorías. IRECTOR.-(De pie, agita su campanilla). ¡Silencio, señores, por favor! (El público se calla). Luego de este admirable discurso de nuestro Catedrático de Prima de Matemáticas, don Cosme Bueno, discurso que pasarả sin duda a los anales de esta universidad, tendremos ocasión de escuchar la respuesta del objetado, señor de Cárdenas...

EN LA GALERIA.-¡No! ¡Que no hable! ¡Que se calle! ¡Basta de cuentos! iQue lo echen afuera!

DIRECTOR.-(Agitando la campanilla). ¡Calma, distinguido público! No podemos contravenir los reglamentos de los debates. (A Santiago, que se levanta en el más profundo silencio). Tiene Ud. la palabra, señor de Cárdenas.

SANTIAGO.-Señores miembros del Cuerpo Docente. (A las Galerias). Distinguido público. (Pausa). He querido dedicar mi invento a $\mathrm{mi}$ patria, el Perú, y a la ciudad de Lima, donde he nacido. Pero me ha bastado ingresar en esta ilustre sala, para sentirme extraño, como si no estuviera en mi país, sino más bien en un país extranjero. Todo inventor, por naturaleza, es un extranjero. Mi memoria no ha tenido la acogida que esperaba ni entre los profesores de esta Universidad ni entre mi querido pueblo. Creo aue no me entretendré en refutar los especiosos argumentos del profesor Cosme Bueno.

Carecen de réplica porque carecen de realidad. (Protestas en las Galerias). 
COSME B.-(Interrumpiendo). ¿Ha leido usted a Juanini?

SANTIAGO.-No, señor doctor. Ignoro quién es ese autor y probablemente lo ignoraré toda mi vida. Pero por más que este autor y otros que usted sabe de memoria, digan, no cejaré en mi empeño. Para volar, felizmente, no es necesario saber griego ni latín. Lo que yo pido solamente es que se me dé la oportunidad de poner en prácticas mis teorias. Ustedes con sus retóricas y su arte de la discución son capaces de probarlo todo o negarlo todo. Pero yo quiero meclirme con ustedes en el terreno de los hechos. Es en ese terreno donde pienso salir victorioso.

DIRECTOR.-iSe matará usted! No queremos echar sobre nuestros hombros tamaña responsabilidad.

SANTIAGO.-El que muera o no, corre por mi cuenta. ¿Qué importancia tendria mi mucrte? Además, y quiero insistir sobre esto, yo no sostengo que mi sistema de navegación sea perfecto. Debe tener muchos defectos, pero de ellos sólo podremos percatarnos cuando lo pongamos en práctica. Si tengo que sacrificarme, lo harí gustoso. Déjeme al menos la satisfacción de intentar un arte que quizá ocupe a todos los hombres del futuro.

COSME B.-(Al Director). En vista de que el objetado no se constriñe a rebatir mis argumentos, sugiero, señor presidente, que se levante esta Magna Asambla.

SANTIAGO.- ¡Protesto!... ¡Protesto en nombre de la razón!

COSME B.- ¿La razón, señor, está en los libros y usted no ha leído nada!

SANTIAGO.- ¡Protesto en nombre de la libertad de investigación!

COSME B.- iHay cosas, señor que no deben ser investigadas porque sus premisas son falsas y contrarian las leyes de la naturaleza!

SANTIAGO_- ¡Hago Ga promesalde autorizar el embargo de mis bienes, a favor de las personas que me faciliten los medios, para llevar a cabo $\mathrm{mi}$ invento $\mathrm{y}$ de pagar con presidio lo que adeudare.

COSME B.- iDe qué presidio habla usted si no sobrevivirá a sus ensayos? ¡Su proyecto, en una palabra, es una locura!

EN LA GALERIA.-¡Una locura! ¡Eso es! ¡Santiago el pajarero ha perdiclo el seso!

DIRECTOR.- (Agita la campanilla). Señores, se levanta la Asamblea! (Alboroto en la galería. El Cuerpo Docente se pone de pie. El público también)

SANTIAGO.-(Gritando) ¡Una locura! ¡También decian que Colón estaba loco cuando se lanzó en tres carabelas a conquistar las Indias! ¿Y ahora ustedes viven, lucran, digieren, discuten y mueren en estas Indias inventadas por Colón! (El Cuerpo Docente comienza a abanclonar la escena por la izquierda. El público abandona la galeria abuchando a Santiago) ¿Una locura porque arriesgo mi vida? También es locura lidiar a los toros, bañarse en la mar, jugar a los da- 
dos, batírse en duelo. $¡ Y$ todo ello está consentido y autorizado por las leyes! iLocura es la de ustedes, señores doctores! ¡No hay locura más incurable que la prudencia! (El publico que sale se burla de Santiago).

UN CHUSCO.- ¡Santiago el volador!

OTRO.- ¡Santiago el loco!

OTRO.- ¡Santiago el mentiroso!

(El publico abandona la sala. Quedan de pie, Santiago, y detris, suyo Rosaluz y el Duque de San Carlos. Rosaluz sale rapidamente por la izquierda seguida del Duque. Santiago queda solo, immóvil al centro de la sala. Un bedel comienza a reacomodar las sillas. Solre la mesa verde encuentra el manuserito de Santiago que lo han dejado olviaado. Tomándolo se acerca al pajarero.)

BEDEL.-No olvide su manuscrito, señor inventor. Ya vanos a cerrar la puerta. (Santiago despierta. Coge su manuscrito y se retira lentamente por la izquierda).

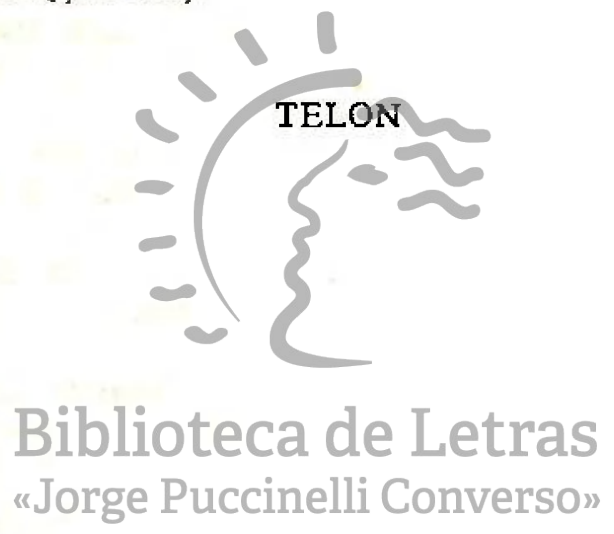




\section{CUADRO QUINTO}

\section{EN EL PORTAL DE BOTONEROS}

Medio dia. Santiago en su tienda da de beber a sus aves.

\section{ESCENA PRIMERA}

MARIA.-iEstá Ud. ahí, maese Santiago? Buenos dfas le dé Dios. SANTIAGO.--Te esperaba, María. ¿Tienes alguna noticia?

MARIA._ ¡Nada, vuesa merced! ¡Ni que lo hubiera tragado la tierra a su amigo Basilio! He recorrido todos los mesones que hay Abajo el Puente. ¡He entrado hasta en las tabernas! Por ningún sitio lo han visto. Dicen que a lo mejor la muerte se lo ha llevado a su madriguera.

SANTIAGO.- ¡Qué extraño! Desde la noche de la serenata no ha vuelto a dar señales de vida. Temo por él. En materia de amor es imprudente $y$ no le arredran títulos ni pelucas.

MARIA_-Si yo fuera dueña de mi tiempo, maese Santiago, seguiría buscándolo. ¡Pero, Ave Mafia Purisima, con todo lo que tengo que hacer! De todos fnodos si usted ime necesita para algo ya sabe don. de encontrarme: en la Iglesia de las Nazarenas, en la misa de seis.

SANTIAGO.-Anda con Dios, María, y te agradezca de todo corazón tus servicios. (Maria conienza a salir). Espera... (Vacila). ¿Podrías darle una comisión a Rosaluz?

MARIA.-(Se acerca). ¡Ay, maese Santiago! (Acongojada) Vuesa merced haría mejor en no pensar en ella. Mi ama ha cambiado mucho ... Sobre todo ahora, que toda la ciudad se burla de Ud. y que hasta le inventan canciones... ¿Qué ha pasado, maese Santiago? Yo no entiendo de estas cosas, pero dicen por allí que es usted capaz de hacer volar a los hombres.

SANTIAGO-Así es, María. He tenido la locura de afirmar eso. Y lo peor es que todavia lo sigo afirmando.

MARIA.-Si es así, maese Santiago, ¿por qué no nos da unas alas a mí $\mathrm{y}$ a todos mis hermanos negros?

SANTIAGO.-(Sonriente) ¿Para qué?

MARIA.-Nos iríamos volando y no volveriamos jamás. ¡Debe ser 
hermoso no tener dueño, como los pájaros, y volar libremente por toda la tierra!

SANTIAGO.-Lo que dices es cierto. Muchas cosas tienen que suceder. Tú $\mathrm{y}$ tus hermanos volarản libremente, como los pájaros.

MARIA.- ¡Dios oiga a vuesa merced! Ahora me voy.. Ya sabe, para cualquier cosa, estoy en la Iglesia de las Nazarenas. (Sule por la izquierda. Santiago queda en la puerta de su tienda, pensativol.

\section{ESCENA SEGUNDA}

SANTIAGO.- iMaese Gonzalvez! (El barbero se detiene) ¿Puedo decirle dos palabras?

BARBERO.- $\mathrm{iAh}$, es usted maese Santiago! ¿En qué pucdo servirle? ¡Lástima que me encuentre tan ocupado!

SANTIAGO.-Es algo que le interesa.

BARBERO.- ¿Interesarme a ml?

SANTIAGO.-Veo que está perdiendo usted clientes por falta de espacio.

BARBERO.-No lo crea, maese Santiago. Ellos regresan siempre a mi. manos.

SANTIAGO.- ¿Mantiene usted su oferta por mi local? Necesito una una fucrte suma de dinero.

BARBERO. $\rightarrow A$ h, las vueltas que da el mundo! Me gusta verlo expresarse asi. Pero, mi entrañable amigo, su local ya no me interesa. El Virrey me ha prometido uno mas grande y mejor situado.

SANTIAGO-Veo que le ba cádon en igracia a nuestro honorable pa. trón. ¡Más valiera, en realidad, dedicarse a raspar barbas que a alimentar bellos sueños!

BARBERO.-Por simple curiosidad, ¿cuánto quiere Ud. por su local?

SANTIAGO.-Lo doy por doscientas onzas de oro.

BARBERO.- ¡Bromea usted, maese Santiago!

SANTIAGO.--Por ciento cincuenta.

BARBERO.-Prefiero esperar. Ya seguirá usted bajando. Día a día, conforme se aproxime el momento de su vuelo, la cifra disminuirá. Y cuando Ud. vuele ya no valdrá un céntimo. Hay que tener un espíritu comercial y esperar la mejor ocasión.

SANTIAGO- ¿ ¿Y quién le ha dicho que voy a volar?

BARBERO.- ¡Tarde o temprano, Ud. terminará volando, maese San. tiago! (Se retira).

SANTIAGO-_Pues si Ud. espera esa ocasión para adueñarse de mi locol, le juro que no volaré.

BARBERO.-Ingresando a su negociol. ¿Que no volará? Eso déjclo por mi cuenta. (Entra a la Barberia). 


\title{
ESCENA TERCERA
}

(Al fondio a la derecha se escucha una voz que viene recitando). LA VOZ.-

\author{
Santiago, de Pajarcro \\ Se convirtió en inventor, \\ Ya no le pidan romero \\ Para el pájaro cantor. \\ Santiago, dice el coplero, \\ Gana el cielo con primor, \\ Desde hoy, mi compañero, \\ Es Santiago, el volador.
}

(Aparece Basilio, con su latid y la barba crecida. Santiago se lanza en sus brazos).

SANTIAGO._-iSi no vienes del infierno, no sé de dónde vendrás!

BASILIO.-No te equivocas demasiado. Ayer por la noche los cala-

bozos de la Inquisición me vomitaron. Veo cl sol despliés de cuarenta días y eso me tiene contento. La vida es maravillosa, Santiago. cuando se recupera la libertad.

SANTIAGO.-iY me dirás, por yentura, a qué se debió tu encierro?

BASILIO. - Un vejetc enamoradizo y celoso me salió al paso y porque mi voz le disgustó, me acusó de herejía y de contumelia. Me he librado de una azotaina pública porque abjuré "in vehementi". ¡Pero don Mateo de Amusquíbar me las pagará! ¡Preparo contra él una canción que hará reír a toda la Ciudad de los Reyes!

SANTIAGO.-Ahora me explico por qué Gazón no te encontraba. ¿Sabes que te heJ beche buscari por todas las fonclas y las pensiones de la Villa? En estos últimos dias he necesitado mucho de tu compaiiía. Todos están contra mí. Por momentos me siento abandonado. El dia de la Asamblea en la Sala de San Marcos no había en las galerías un solo rostro amigo que me alentara. Ni siquiera el de Baltazar.

BASILIO.- $i$ Ah, el pobre Baltazar! Lo primero que hice anoche fue pasar por su celda de San Francisco. ¿Me creerás si te digo que ha perdiclo el juicio? Los monjes dicen que es por efecto del vino. Pero lo cierto es que ha esculpido una figura de darle susto a cualquiera. El mismo debe haber quedado espantado de su obra. Está sin conciencia y no reconoce a nadic,

SANTIAGO.—Válgame Dios! Los santos nos han dado la espalda. ¿Qué será de nosotros Basilio? En este mundo no se pucde vivir. Todo aquel que tiene algo nuevo que decir, algo grandioso que crear, despierta la envidia y la maledicencia de las gentes, y no lc queda otro recurso que renunciar a sus designios o morir.

BASILIO._(Señalando hacia la izquierda). [Mira, alli viene Rosaluz! 
SANTIAGO--¡Por las dicz mil virgenes! ¡Y mi tienda está toda desarreglaca!

(En ese momento asoma Rosaluz del brazo del Duque de San Carlos).

\section{ESCENA CUARTA}

DUQUE-En estos dias estara lista mi carroza. Podremos entonces ir a pasear por las huertas de Miraflores y Chorrillos. Por aquellos lugares se dan las mejores frutas.

BASILIO.-(Con una reverencia). Buenos días, Rosaluz. (Rosaluz no contesta el saludo y vtielve el rostro hacia el otro lado).

DUQUE.-iConoces a ese mozo?

ROSALUZ-No. Debe ser algún bohemio impertinente. (Sigten caminando y desaparecen por la derecha. Santiago asoma en ese momen. to por la trastienda).

SANTIAGO.--¿Pasó ya?

BASILIO.-Parecía tener mucha prisa. (Santiago sale a la vereda y mira hacia el lado por la cual ha desaparecido). SANTIAGO.-(Pensativo). En efecto, demasiada prisa.

BASILIO-(Recitando). ¿Qué cuidado me da a mi Que pases $\mathrm{y}$ no me hables,

$\mathrm{Bib}$ Si sabes que yo no como

Con buenos dias de nadie?

"Jorgendac vete lque novguiero

Pasar por ti más faligas;

¿Si digo que no te quiero,

Que más quieres que te diga?

SANTIAGO.-Basilio, ya estoy decidido.

BASILIO.- ¿A qué cosa, mi querido inventor?

SANTIAGO.-Te lo diré en dos palabrás. ¿Te habrás enterado que Cosme Bueno rechazó mi memoria?

BASILIO.-Algo he oído de eso en el camino.

SANTIAGO.-Bien, he escrito una nueva memoria. Pero no está diri. gida al Virrcy, sino a su Majestad Felipe V.

BASILIO-_ ¡Magnífico! ¡Con toda seguridad, en la Corte de Madrid te dispensarán mejor atención.

SANTIAGO.--Sí, pero necesito viajar a la metrópoli.

BASILIO.- ¿Y cómo harás para ello? El viaje es largo y costoso.

SANTIAGO.-En estos días zarpa un bajel para Panamá. Pensaba enrolarme como grumete, pero es imposible. (En ese montento et 
barbero sale de su tienda y se detiene a la de Santiago. Al sentir las voces se detiene cerca de la puerta y escuchal. El Duque de San Carlos iba a ofrecerme su ayuda, pero está visto que ya no le interesa verme fuera de Lima. ¡Lo que haré será vender mi tienda! Pero no al mezquino Barbero, mi vecino. La daré a cualquier otro aunque sea a cien onzas de oro. (El Barbero se retira hacia su ne. gocio) Pero me faltará un poco de dinero. En ese problema me encuentro.

BASILIO.- FHabrá que conseguirlo de donde sea! Se trata de una em presa tan importante, que yo sería capaz de vender mi alma al diablo, si es que algún diablo quisiera hacerse cargo de ella. (Caviloso) ¿Qué cosa podríamos hacer?

SANTIAGO.-No sé, Basilio. ¿Y lo peor es que solo me quedan tres días para arreglar mi viaje.

BASILIO.-iEspera! (Se gotpea ta frente) Tengo una idea. ¿Sabes que en el calabozo para consolarme de mi dolor escribi una alegre comedia? ¿Iré a ofrecerla a Federico Meza! Estoy seguro que me dará, por lo menos, unos cincuenta pesos ensayados.

SANTIAGO.- ¿Lo crees posible?

BASILIO.-Escucha: lo que te digo es posible. Federico Meza me dara aunque sea adelantado sobre palabra. El siempre se ha interesado por mis coplas y es hombre de confianza.

SANTIAGO.-Al menos, vale la pena hacer la tentativa.

BASILIO.-iClaro que vale la pena! Espérame en tu tienda, pero a puerta cerrada. Yo vuelvo en un abrir y cerrar de ojos. Ten con. fianza en mí. Santiago, que todo esto se arreglará.

SANTIAGO-_Te Tesperaré ansioso, Basilio! +Basitio deja su latid $y$ sale rapidamente por la izqnierda. Santiago to ve alejarse y luego penetra en su tienda y cierrantas puertasherso"

\section{TELON}




\title{
CUADRO SEXTO
}

\section{EN EL PORTAL DE BOTONEROS}

\section{ESCENA PRIMERA}

Un grupo de chiquillos del pueblo aparece por la izquierda y se de. tiene delante del negocio de Santiago.

CHIQUILLOS.-(Cantando a coro).

\author{
Cuando voló una marquesa, \\ Un fraile tambićn voló, \\ Pues recibieron lecciones \\ De Santiago el Volador. \\ ¡Miren qué pava para el marqués! \\ ¡Miren qué pava para los tres!
}

SANTIAGO.-(Sale de la tienda) ¡Fuera de aquí granujas!... ¡Otra vez. fastidiando la paciencia! ¡Los haré azotar si continúan burlándose de mí! ¡Bien harian sus padres en darles de comer en lugar de enseñarles canciones groseras! (Los chiquillos corren hacia la derecha, riéndose).

UN CHIQUILLO._¿Cuándo nos enseña a volar, maese Santiago?

OTRO CHIQUILLO.- ¿Es cierto que su novia ha volado con un Duque? SANTIAGO._iFuera, he dicho!

(El coro de muchachos desaparece. Santiago ingresa a su tienda) .

\section{ESCENA SEGUNDA}

(De la Barbería salen dos clientes acompañados por el barbero. El barbero echa una mirada hacia la tienda de Santiago y ve las puer. tas cerradas. Se acerca y queda caviloso. Se vuelve hacia la izquierda y llama a los dos clientes).

BARBERO.- ¡Eh, acérquense, señores! ¿No saben la última nucva? ¡Es algo verdaderamente inverosímil! (Los clientes aparecen intrigados) Pero sean discretos, que se trata de un importante secreto. CLIENTE 1.- ¡Pero dígalo de una vez, maese Gonzalveśl 
BARBERO.-Hoy día justamente a las doce Santiago el Pajarero vo lará.

CLIENTE 2.-Pero, ¿cómo lo sabe usted?

BARBERO.- ¿No ven la puerta de su tienda? Está cerrada. Muy de mañana lo vi salir con un extraño instrumento sobre los hombros Tomó el camino del puente. De fijo iba hacia el San Cristóbal.

CLIENTE 2.- ¿Y desde aquel cerro volará?

BARBERO.--iSobre toda la Ciudad de los Reyes!

HOMBRE.- ¿Qué alboroto es éste, maese Gonzalves?

BARBERO.-Santiago volará a medio día. Yo les cuento lo que he visto. Desde hace tiempo se traía algo entre manos.

CLIENTE 1.-Habrá que ir a las faldas del cerro! (Pasa un grupo de hombres por las calle) Eh. señores, ¿no saben la buena nueva? ¡Santiago el pajarero va a volar a medio día desde el Cerro San Cristóbal.

BARBERO.-Amat se lo ha prohibido. Pero Santiago quiere salirse con la suya. Repito: temprano lo vi tomar el camino del San Cristóbal.

HOMBRE 1.-Pcro, ¿cómo? ¿Entonces Amat lo ha autorizado?

HOMBRE 2.- ¡Se matará sin duda!

CLIENTE 2.-Eso habrá que verlo de cerca. ¡Vamos al San Cristóbal!

BARBERO.- ¡Miren! (Señalando hacia donde se presume se encuentra el cerro). ¿No ven ustedes un punto que se mueve?

CLIENTE 2.- ¡Es verdad! ¡Debe de ser Santiago! ¡Desde aquí distingo su sombrero!

BARBERO.- iEs Santiago que ya se apresta a ganar la cumbre!

TODOS.-_Vamos allá, señores! (Salen por la izquierda. Dos hombres vienen por la derecha y se detienen ante la barberia).

HOMBRE 3.-¿Qúé alboroto es lesté, maese Gonzalves?

BARBERO.- ¡Vayan al San Cristóbal! ¡Santiago, el pajarero, va a volar! (Hombre 3, agitando los brazos, llama a un grupo que se encuentra a la izquierda, fuera del escenario).

HOMBRE 3.- iVengan, señores! ¡Apúrense, Santiago está en la cima del San Cristóbal y se apresta a volar! ¿Usted no viene, maese Gonzalves?

BARBERO.- ¡Dense prisa, que se perderán el más grande fenómeno de estos tiempos!

(El barbero se esconde. Aparece Santiago).

SANTIAGO.- ¿Por ventura qué cosa es lo que sucede?

HOMBRE 3.-(Reconociéndole). Pero, ¿cómo? ¿estás tú aquí?

SANTIAGO. $-i A$ dónde va toda esa gente?

HOMBRE 3.- ¿Tú no eres el que ibas a volar?

SANTIAGO._- ¿Volar yo? ¿Quién les ha contado ese cuento?

HOMBRE 3.- iAquí está Santiago! ¡Todo es una mentira!

HOMBRE 4.-¿Cómo? ¿Nos has engañado? ¿Que vuele o lo matamos a pedradas! 
HOMBRE 3.- ¡Llevémoslo al cerro! (Se acercan amenazadores).

SANTIAGO.-iQuieren dejarme tranquilo, por ventura? (Los hombres se acercan mis).

HOMBRE 3.-iLlevémoslo al San Cristóbal!

SANTIAGO.-(Retrocediendo hacia su tienda). ¿Qué daño les he hecho yo para que me hostiguen?

HOMBRE 4.-Dijiste que ibas a volar y ahora tienes que hacerlo.

HOMBRE 3.- iCuidado, que quiere encerrarse en su tienda! (Hombre 3 corre y le cierra la puerta).

SANTIAGO.- ¡Han sido victimas de un engaño! ¡Déjenme!

HOMBRE 3.- ¡No lo sueltes! ¡Que vuele! ¿Cómo nos vamos a dejar embaucar?

HOMBRE 4.-¿Qué prefieres, volar o que te colguemos?

HOMBRE 3.- ¡Llevémoslo al San Cristóbal!

LOS DOS.-¡Santiago está aquí! ¡Santiago está aquí!

(Santiago logra safarse y corre hacia la derecha. Lo persiguen los gritos de: "cojan al loco Santiago", "queremos verlo volar", "piedras con el". Los gritos se pierclen por la derecha. El barbero, en la puer. ta de su tienda observa la persecución. Gritan: "Alli se llevan a San. tiago", "ya lo cogieron al volador" Basitio aparece).

BASILIO.- ¡Santiago! ¡Santiago! ( $A l$ barbero). ¿Dúnde está Santiago? ¿Es cierto lo que dice la gente?

BARBERO.-(Con parsimonia). La turba lo ha perseguido. Lo van a hacer volar desde el cerro San Cristóbal. (Señala hacia donde vienen gritando desaforados).

BASILIO.-(Con rabia). iAsesinos! (Desaparece a la carrera por la de. recha. El barbero se acerca a la tienda de Santiago y cuenta con los pasos la extensiónode su fachada Lilego quedas caviloso contemplando la puerta. Los gritos, a la izquierda, van disminuyendo en intensidad. Pronto, sólo se escucha el silencio. Al poco rato aparece Basilio con la capa desgarrada, cargando el cuerpo de Santiago. Lo deposita delante de su tienda y se arrodilla a su lado. Le cruza los brazos sobre el pecho y recita la Copla del Inventor. Mientras Basilio recita, el barbero ha salido con su cartelón que colocará en la puerta de la tienda de Santiago, en el cual dice con grandes letras: "Perfumería Real" - "Esteban Gonzalves").

\section{COPLA FINAL}

Favores pidió a virreyes

$Y$ no los pudo lograr;

En medio de tantas leyes

Fue su delito soñar,

Soñar con poder volar. 
Volando alcanzan la cima

Miserables convenidos,

Que sólo triunfan en Lima

Los vestidos de bandidos.

Quienes no saben soñar

Se arrastrarán por el suelo,

Mientras tú llegas al cielo

Con que soñaste al volar.

$Y$ asi a pesar de tu duclo

$\mathrm{Si}$ tu sueño fue volar

Nadie te podrá olvidar.

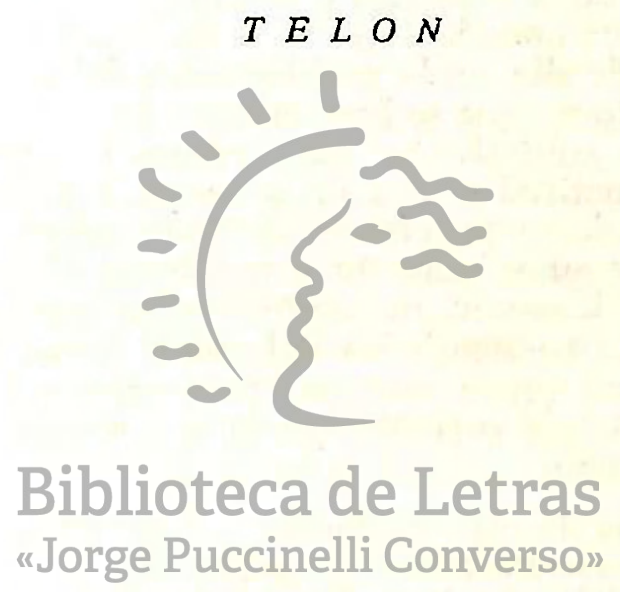

